\title{
A Minute with Emanuel Derman
}

In each issue, Algorithmic Finance features a brief interview with one member of our advisory or editorial boards or another leading academic or practitioner. These brief conversations are intended to provide a glimpse of their current thinking. Our first discussion is with Emanuel Derman.

EMANUEL DERMAN is Head of Risk at Prisma Capital Partners and a professor at Columbia University, where he directs their program in financial engineering. His latest book is Models.Behaving.Badly: Why Confusing Illusion with Reality Can Lead to Disasters, On Wall Street and in Life. He is also the author of My Life As A Quant, one of Business Week's top ten books of the year, in which he introduced the quant world to a wide audience.

He was born in South Africa but has lived most of his professional life in Manhattan, where he has made contributions to several fields. He started out as a theoretical physicist, doing research on unified theories of elementary particle interactions. At AT\&T Bell Laboratories in the 1980s he developed programming languages for business modeling. From 1985 to 2002 he worked on Wall Street, running quantitative strategies research groups in fixed income, equities and risk management, and was appointed a managing director at Goldman Sachs \& Co. in 1997. The financial models he developed there, the BlackDerman-Toy interest rate model and the DermanKani local volatility model, have become widely used industry standards.

In his 1996 article "Model Risk," Derman pointed out the dangers that inevitably accompany the use of models, a theme he developed in My Life as a Quant. Among his awards and honors, he was named the SunGard/IAFE Financial Engineer of the Year in 2000. $\mathrm{He}$ has a $\mathrm{PhD}$ in theoretical physics from Columbia University and is the author of numerous articles in elementary particle physics, computer science, and finance.
He blogs at http://blogs.reuters.com/
emanuelderman/

\section{What are your research interests right now?}

I tend to work on things that crop up in managing the risk of alternative investments, related to part time work at a fund of funds I've been involved with since 2004. A fund of funds has very practical but difficult problems to which, mostly, there isn't some elegant mathematical solution. So, for example, I've done work on the value of liquidity - how much excess return you should expect for letting a hedge fund lock up your money for three or more years. Similarly, right now, I've been working on a methodology for evaluating so-called tail risk in hedge funds, which aren't as market neutral as they would like to pretend. Most of the inspiration for this comes from talking to portfolio managers. I like to use options and volatility theory to look at these questions.

What do you see as academically exciting?

I'm attracted to two things at opposite ends of the spectrum. One is the econophysics or agent-based approach to modeling markets, which tries to look at collective effects. It seems to me these models have hope of providing some insight into the consequences of many individuals doing similar things. And then, I like trying to find simple ways to explain financetheoretic principles. I dislike the arcane way that finance has headed. If you look at Einstein's derivation of the special theory of relativity, the math is pretty simple. It's based on a principle you can state in words: that the laws of nature must look the same in all inertial frames. General relativity has much more difficult math, but the principle is still easily articulated: laws must look the same in any frame, even an accelerating one. That said, it's a bit of a pipe dream to imagine one can do something like that in finance. But nice to think about.

What would you work on if you had lots of time? A novel. 